\title{
THOMAS KUHN NA EPISTEMOLOGIA DA CIÊNCIA DA INFORMAÇÃO: UMA REFLEXÃO CRÍTICA
}

\section{THOMAS KUHN EN LA EPISTEMOLOGÍA DE LA CIENCIA DE LA INFORMACIÓN: UNA REFLEXIÓN CRÍTICA}

Gustavo Silva Saldanha - gustavosilvasaldanha@gmail.com

Fundação Biblioteca Nacional

\begin{abstract}
Resumo
Este trabalho discute a presença de Thomas Kuhn nas Ciências Sociais e na Ciência da Informação. Identifica possíveis incongruências no uso de teorias da filosofia da ciência baseada na obra "Estrutura das Revoluções Científicas" no âmbito da leitura epistemológica dos estudos informacionais. Desenvolve uma reflexão crítica sobre a epistemologia e a historiografia da Ciência da Informação.
\end{abstract}




\section{INTRODUÇÃO}

O filósofo da ciência Thomas Kuhn marcou o pensamento epistemológico ocidental com a publicação, em 1962, da obra A estrutura das revoluções científicas ERC. A dispersão de seu pensamento por diferentes campos do conhecimento foi rápida e profunda. O conceito de paradigma, formulado pelo autor, passou a figurar em revisões e análises de disciplinas que vão das ciências exatas às biológicas e sociais. A ampla adoção da filosofia kuhniana se deu por inúmeros motivos, tendo sua especificidade determinada em cada contexto de inserção e uso.

O empréstimo ilimitado, por vezes acrítico, do conceito de paradigma segundo o olhar de Kuhn é tema dessa breve reflexão. Pontuando alguns elementos conflitantes da leitura do progresso da ciência empreendida pelo autor, delimitamos nossa análise na adoção da ERC nas ciências sociais, procurando fundamentar nosso recorte no horizonte final desse trabalho: a presença de Kuhn na Ciência da Informação - Cl. Utilizado na descrição epistemológica das ciências sociais em geral e, por extensão, da $\mathrm{Cl}$, reproduzindo-se em artigos, capítulos e livros, o filósofo nos traz uma obra profunda e polêmica, sempre carente de releituras críticas.

A importância de Kuhn para a filosofia da ciência é identificada a partir de diferentes evidências quantitativas e qualitativas.
Como lembra Rorty (1997), a distinção entre ciência e não-ciência foi minada com o tratado filosófico mais influente do mundo anglófono nos últimos cinqüenta anos: a ERC. Em Laudan et. al. (1993) temos a lembrança de que a história da ciência avançou muito após a metade do século $X X$, principalmente com o prestígio atingido pela obra kuhniana. No âmbito das ciências sociais, podemos citar a presença de Kuhn em autores como Santos (1993) e Touraine (2006). No contexto específico da $\mathrm{Cl}$, temos, por exemplo, manifestações em nomes de pesquisadores como Foskett (1980), Lenzi e Brambilla (2006), Matheus (2005), Nehmy et al. (1996) e Capurro (2003).

Acreditamos ser de grande relevância discutir o modelo de desenvolvimento da atividade científica segundo a ótica de Kuhn no âmbito das ciências sociais e, principalmente, da $\mathrm{Cl}$, pois essa argumentação conduz até uma discussão mais ampla na epistemologia informacional. Ela permite abrir caminho para exploração de alguns pontos importantes no estudo epistemológico da $\mathrm{Cl}$, como aprofundar as discussões sobre a cientificidade da área; propor noções sobre a classificação das movimentações epistemológicas dos estudos informacionais; desvelar pontos críticos no posicionamento da $\mathrm{Cl}$ como disciplina social e aplicada; rever os discursos de justificação meta-científica na epistemologia informacional; e contribuir para dife- 
rentes olhares na construção de uma historiografia exaustiva e crítica dos estudos da informação.

\section{PARADIGMAS SEGUNDO THOMAS KUHN: EM DIREÇÃO ÀS CIÊNCIAS SOCIAIS}

A partir de uma leitura crítica sobre o empréstimo do conceito kuhniano de "paradigma" realizado pelas ciências sociais, Assis (1993) ${ }^{1}$ aponta que a importação da poli-semântica acepção, produzida com um olhar sobre as ciências naturais, causou tanto esclarecimentos quanto profundas confusões. Com a publicação do clássico trabalho de Thomas Kuhn, a ERC, a dispersão discursiva do conceito de paradigma, grande categoria de análise da obra, ocorre sobre diferentes disciplinas, mesmo diante da pluralidade de significados que sua revisão desdobraria.

Kuhn (1975, p. 218), no posfácio de sua obra, confere ao termo "paradigma" dois sentidos diferentes: de um lado, o vocábulo remete à constelação de crenças, valores e técnicas partilhadas pelos membros de uma comunidade determinada; de outro, denota um tipo de elemento dessa constelação. Em ambos, o conceito está vinculado ao período da atividade científica que chama de "ciência normal" (KUHN,

1 Jesus de Paula Assis é físico, mestre em Sociologia, doutor em Ciências Sociais e desenvolveu seu pós-doutourado na Escola de Comunicação e Artes da USP.
1975, p. 30). Como argumenta Assis (1993, p. 135),

$$
\begin{aligned}
& \text { Kuhn divide o desenvolvimento } \\
& \text { científico de uma disciplina } \\
& \text { particular em dois grandes } \\
& \text { componentes: ciência normal e } \\
& \text { revolução científica. Durante os } \\
& \text { períodos de ciência normal, os } \\
& \text { cientistas concordam acerca dos } \\
& \text { fundamentos de sua disciplina [...]. } \\
& \text { Já nos períodos de revolução } \\
& \text { científica, acontece o debate entre } \\
& \text { alternativas rivais, no qual os } \\
& \text { participantes de cada escola } \\
& \text { baseiam seu discurso em conjuntos } \\
& \text { diferentes de fundamentos. [...] O } \\
& \text { debate não é racional, no sentido } \\
& \text { de sempre esbarrar em questões } \\
& \text { que não podem ser resolvidas de } \\
& \text { comum acordo entre as partes, } \\
& \text { recorrendo ambas a um foro neutro } \\
& \text { e reduzindo seus diferentes } \\
& \text { discursos a um comum, via } \\
& \text { mecanismos inteiramente lógicos. }
\end{aligned}
$$

Ao longo da ERC registra-se que uma atividade científica se torna paradigmática quando cessa o debate em torno dos seus princípios, ou seja, quando há uma espécie de ecumenismo provisório para tal consenso, um acordo em torno do objeto único, validável e promissor. O que antecede esse acordo pode ser considerado um debate desorganizado, vindo de diferentes visões de mundo (KUHN, 1975). Como indica Kuhn (1975, p. 35),

[...] na ausência de um paradigma ou de algum candidato a paradigma, todos os fatos que possivelmente são pertinentes ao desenvolvimento de determinada ciência têm a probabilidade de parecerem igualmente relevantes. Como conseqüência, as primeiras coletas dos fatos se aproximam muito mais de uma atividade ao acaso do que daqueles que o 
desenvolvimento subseqüente da ciência torna familiar ${ }^{2}$

Há um momento em que uma dada escola ganha uma evidência consideravelmente vultuosa, e derruba as demais. A partir do momento em que a competição dá lugar à estabilidade de um consenso epistemológico, o paradigma da escola que saiu vencedora é assumido em uma aceitação comum, tornando-se a estrutura de uma tradição. Definida a via de um paradigma único - ou, diante da atualização da promessa de sucesso do paradigma - inicia-se a fase chamada "ciência normal". Aqui os cientistas têm por tarefa aperfeiçoar padrões de medida, o cálculo das constantes da teoria e ampliar o campo de aplicação do modelo. Nesse momento, não há confronto entre teorias rivais. A decisão racional entre duas saídas é inconcebível, pois o paradigma carrega consigo seus próprios métodos de avaliação. Aquilo que pode resistir como

2 Assis (1993, p. 137) demonstrará que esta visão kuhniana da ingenuidade inicial da pesquisa, refém do acaso e não da sistematização crítica, também pode ser apontada no estado de maturidade científica do modelo da Estrutura das Revoluções Científicas, pois "nenhuma teoria nova está de acordo com todos os fatos já conhecidos do campo que pretende explicar. Essa característica das teorias científicas é reconhecida, seja por um positivista lógico ortodoxo, seja por um filo-anarquista em epistemologia. Assim, quando a comunidade aceita um paradigma, o que ela está aceitando é, na verdade, uma promessa de resolução de problemas futuros, promessa que se impõe sobre as outras com base no sucesso obtido na resolução dos problemas já examinados. Nesse sentido, pode-se também dizer que a aceitação de determinado paradigma é um fenômeno irracional: ele é aceito menos pelo que fez no passado e mais pelo que se sente ele poderá fazer no futuro". elemento não participante do paradigma, será chamado de "anomalia". A princípio, as anomalias ficam renegadas, reservadas para um momento posterior incerto. Essa data pode guardar o olhar de um pesquisador ou grupo de pesquisadores de prestígio, que, verificando o esgotamento do paradigma, voltar-se-ão para uma dada anomalia que está na encruzilhada de certos caminhos para solução de problemas. (KUHN, 1975).

Desta forma,

[...] não há como pesar racionalmente todos os fatores a serem levados em conta na decisão de se abandonar ou não um paradigma, via regras explicitáveis e que devam ser aceitas por todos, sob pena de acusação de inconsistência ou irracionalidade para quem não as admita. Os ligados a prestígio dispensam comentário. Mas também não é possível decidir quanto é muito tempo para que um problema resista à solução, ou o quanto um problema é central dentro de uma teoria. Do ponto exclusivamente lógico, não há como definir univocamente tais questões. (ASSIS, 1993, p. 139).

No âmbito das ciências sociais, como afirma Assis (1993, p. 146), a ERC foi adotada

[...] como um manual para descobrir, de modo mecânico, ciências paradigmáticas ou ciências em vias de paradigmatização. Notadamente nas ciências sociais, surgiram autores que, apoiados num mal compreendido Kuhn, descobriram que elas são tão ciência quanto as ciências naturais, visto que possuem paradigmas.

De modo crítico, Assis (1993) defende que essa importação parte da facilidade 
de acesso ao livro, diferente de outros textos em filosofia da ciência, e da posição política de prestígio que a ciência ocupa na sociedade contemporânea. Mas talvez seja a questão mais importante a "necessidade aparente que as ciências sociais têm de se mostrar científicas", tomando, por isso, Kuhn como seu principal apoio argumentativo. (ASSIS, 1993, p. 147)

Há, além disso, a questão da presença de Kuhn no contexto da filosofia científica como uma propícia alternativa ao pensamento do progresso científico oferecido por Karl Popper (ASSIS, 1993, p. 157). Para Popper (1975) há quatro procedimentos para a provação da teoria: 1) comparação lógica das conclusões entre si, através do qual se testa a consistência interna do sistema; 2) investigação da forma lógica da teoria, com intuito de determinar o seu caráter - empírico, científico ou tautológico; 3) comparação com outras teorias, na busca por determinar se a teoria constituiria um avanço científico, caso sobrevivesse aos testes; 4) aplicações empíricas das conclusões que se podem deduzir dela. Esses procedimentos fundamentam sua teoria da falseabilidade. É necessário, pois, distinguir, por um lado, as experiências subjetivas ou sentimentos de convicção, que não podem justificar qualquer enunciado e, por outro lado, as relações lógicas objetivas existentes entre os sistemas de enunciados científicos e no interior de cada sistema. Enquanto Popper exclui essas experiências e sentimentos da atividade científica, Kuhn procura demonstrar que eles são fundamentais ao desenvolvimento científico.

Esses elementos críticos apontados caracterizam a necessidade de uma revisão da utilização do pensamento de Kuhn dentro da $\mathrm{Cl}$, ciência social aplicada que tende a importar inúmeros conceitos das ciências sociais e humanas em geral. Recentemente, Nehmy et al. (1996), Eugênio, França e Perez (1996), Capurro (2003), Lenzi e Brambila (2006) realizaram trabaIhos dentro da $\mathrm{Cl}$ que fizeram o uso do pensamento de Kuhn ou interpretaram a visão de mundo kuhniana aplicada à área.

Capurro (2003) parte da tese da ERC e classifica a história da epistemologia da $\mathrm{Cl}$ a partir de três grandes paradigmas: $\mathrm{O}$ físico, o cognitivo e o social. Em Nehmy et al. (1996), seguindo um olhar oposto, a leitura da visão do desenvolvimento da ciência segundo Kuhn indica a $\mathrm{Cl}$ como uma ciência carente de amadurecimento, ou seja, carente de paradigmas. Os autores buscarão em Kuhn o suporte para refletir o estatuto científico da área, investigação realizada por outros cientistas sociais, como apontou Assis (1993). Eugênio, França e Perez (1996) partem do pensamento kuhniano para construir a definição de $\mathrm{Cl}$. No cerne dessa construção, os pesquisadores afirmam, também em um olhar oposto ao de Capurro (2003), não existirem paradigmas dentro da área. "Não há na $\mathrm{Cl}$ algo 
que Kuhn chama de paradigma, alguma idéia que seja consensual, hegemônica [...]. Nota-se já uma busca por uma fundamentação teórica forte que sustente a $\mathrm{Cl}$, mas que ainda não existe de modo bem definido" [...] (EUGÊNIO; FRANÇA; PEREZ, 1996, p. 34). Desta forma, os pesquisadores imaginam a área, assim como Nehmy et al. (1996), como uma ciência aprendiz - imatura, no vocabulário kuhniano -, "em busca de um paradigma que dê sustentação e abra horizontes para o estudo e a pesquisa". (EUGÊNIO; FRANÇA; PEREZ, 1996, p. 34).

Eugênio, França e Perez (1996) defenderão que, dentro da ciência social aplicada que é a $\mathrm{Cl}$, os cientistas, além de afirmar o paradigma vigente - que ainda estaria por se definir - precisavam fundamentar a teoria consensual com um resultado prático. Lenzi e Brambila (2006) partem, até certo ponto, do mesmo olhar de Eugênio, França e Perez (1996) e Nehmy et al. (1996), indicando que, sendo a $\mathrm{Cl}$ uma ciência jovem, há na área uma grande gama de discordâncias, o que inviabiliza a constituição de um paradigma, ou seja, para os autores a disciplina, dentro da ótica kuhniana, também se configura como imatura. Percebe-se o espectro de diferenças no uso do pensamento kuhniano sobre atividade e do progresso científico. Essas diferenças se tornam mais complexas quando é realizada uma revisão da historiografia da $\mathrm{Cl}$, ou seja, dos modelos de narrativa que nos contam o desenvolvimento da área. A adoção do modelo paradigmático da ERC revelará uma maneira totalmente diferente de conceber a história da $\mathrm{Cl}$. Procuramos, nas seções seguintes, refletir sobre os problemas que tais evidências podem conduzir e as perspectivas abertas por outros olhares.

\section{OS PARADIGMAS NAS CIÊNCIAS SO- CIAIS E NA CIÊNCIA DA INFORMA- ÇÃO}

\subsection{A inserção de Kuhn nas ciências so- ciais: uma crítica da arbitrariedade, do dogmatismo e da incomensurabi- lidade}

O estudo de Kuhn (1975) tem como foco a argumentação sobre o conceito "paradigma". Essa argumentação tem, em sua instância principal, a categoria do consenso. O paradigma é, antes de tudo, uma decisão comungada e legitimada por participantes de uma escola de pensamento. Essa noção nos leva ao primeiro elemento conflitante na compreensão do pensamento do filósofo. O mesmo consenso é o objeto que conduz até uma ação dogmática, uma vez que o caráter de arbitrariedade está implícito em sua legitimação entre os pares - definido o consenso, as vozes contrárias são recusadas e é imposto o novo regime de pesquisa. Assim, "um elemento aparentemente arbitrário, composto de acidentes pessoais e históricos, é sempre um ingrediente formador das crenças esposa- 
das por uma comunidade científica específica numa determinada época”. (KUHN, 1975, p. 23)

Esse elemento arbitrário, no entanto, segundo Kuhn (1975), não necessariamente indica que o grupo de pesquisadores sobreviverá sem um conjunto de crenças acumuladas, nem limitará a miríade de possibilidades abertas para a realização dos projetos de pesquisa. Vê-se o caráter antropológico do pensamento do autor contido na ERC, iluminado na idéia de constelação de crenças, valores e técnicas compartilhados. A atividade científica e seu desenvolvimento são vistos a partir de um oIhar sobre a vivência das comunidades acadêmicas. O fazer científico se dá através de uma práxis.

Como somatório de divergências e aproximações, crenças e valores, promessas e satisfações, o desdobramento de uma revolução científica pode ser interpretado com a metáfora de uma revolução social. Uma vez descontentes com o regime vigente, munidos de experiências e observações críticas que corroboram a decadência de um conjunto de leis e deveres, os indivíduos de uma determinada classe identificam a emergência de uma nova agenda. Essa agenda nada mais é do que o novo paradigma que já se faz presente no discurso dessa classe, fruto de um amplo processo histórico-deliberativo. O regime vigente é então deposto e é instaurada uma nova ordem.
Há que se observar criticamente que, diante da metáfora, mesmo na questão da derrubada de um regime de poder, velhas formas de organização social são mantidas, ainda que de maneira tácita. Um novo vocabulário é compartilhado, mas muitos dos velhos e novos conceitos trazem em seu bojo significados semelhantes às palavras depostas. Assim há, em cada revolução, um estado de continuidade em inúmeros elementos culturais - naturalmente, seria impossível a extinção de tais elementos, uma vez que a revolução é, em suma, como o que foi descrito acima, um somatório de ideologias e utopias, e não é possível descartá-las como um instrumento obsoleto.

Outro ponto crítico diz respeito ao desdobramento da argumentação antropológica inicial da noção paradigmática. No decorrer da formulação do conceito de paradigma, Kuhn (1975) conferirá à noção mais singularidade ao caráter arbitrário do que ao caráter alternativo da constituição das revoluções científicas, mais ao caráter competitivo do que ao deliberativo ou consensual. Ao final da leitura da ERC, é mais clara a imagem dogmática e arbitrária de que o consenso elimina o que é marginal ao seu debate, do que a imagem inicial, de ordem antropológica, de que o consenso reinterpreta o pensamento do outro, e reposiciona esse pensamento dentro de uma outra teoria, mais coerente. Se tomásse- 
mos esse itinerário de leitura ${ }^{3}$, poderíamos chegar à conclusão de que a evolução paradigmática das ciências ocorre de "maneira democrática" entre as pequenas comunidades científicas dispersas, porém, sob um "regime de poder totalitário" - ou seja, um regime que sobrevive apenas da exclusão de opiniões, e não de inclusão de diversidades. Como afirma o autor,

quando, pela primeira vez no desenvolvimento de uma ciência da natureza, um indivíduo ou grupo produz uma síntese capaz de atrair a maioria dos praticantes de ciência da geração seguinte, as escolas antigas começam a desaparecer gradualmente.

Seu desaparecimento é em parte causado pela conversão de seus adeptos ao novo paradigma. Mas sempre existem alguns que se aferram a uma ou outra concepções mais antigas; são simplesmente excluídos da profissão e seus trabalhos são ignorados. $O$ novo paradigma implica uma definição nova e mais rígida do campo de estudos (KUHN, 1975, p. 39).

Definido o paradigma, o grupo de pesquisadores que comunga dos mesmos fundamentos desse novo padrão, passa a se orientar unicamente pelo caminho acordado, ou parâmetro. Os pesquisadores convertidos estreitam seu modo de pensar e de fazer ciência ${ }^{4}$, pois uma comunidade,

3 Esta linha não era, a princípio, a pretensão do autor. Thomas Kuhn (1975, p. 49) afirma, categoricamente, que "os esforços para articular um paradigma não estão restritos à determinação de constantes universais".

4 Não há, em Thomas Kuhn (1975), um sentido pejorativo nesse estreitamento. Ao contrário, há a constituição de uma rota segura de pesquisa, na qual $o$ pesquisador se sente protegido para "ao adquirir um paradigma, adquire igualmente um critério para escolha de problemas que, enquanto o paradigma for aceito, poderemos considerar como dotados de uma solução possível". (KUHN, 1975, p. 60)

O caráter de exclusão de teorias e teóricos dentro da ótica paradigmática de Kuhn (1975), a evidência das categorias arbitrariedade e competitividade sobre as categorias alternatividade e deliberação, do dogmatismo sobre descentralização de pensamentos, da incomensurabilidade sobre a comensurabilidade, parecem integrar um paradoxo dentro das ciências sociais. Como afirma o autor, a presença de uma "sólida rede de compromissos ou adesões - conceituais, teóricas, metodológicas e instrumentais - é uma das fontes principais da metáfora que se relaciona à resolução de quebra-cabeças" (KUHN, 1975, p. 65). Isto significa dizer, segundo a metáfora kuhniana, que, dentro dos paradigmas, os problemas são peças a serem identificadas e encaixadas - o paradigma é capaz de prever o quebra-cabeça, é sempre capaz de dizer, pelo menos para essa rede de indivíduos, o que é o quebra-cabeça. O dogmatismo pode ser localizado em seu nível extremo quando Kuhn (1975, p. 66) argumenta que as "regras [...] derivam de paradigmas, mas os paradigmas podem dirigir a pesquisa mesmo na ausência de

mergulhar em uma investigação sem receios 
regras", ou seja, os convertidos são levados por uma promessa, antes de serem sustentados por critérios explícitos dessa promessa, o que reforça o caráter irracional de condução dos paradigmas alertado por Assis (1993).

Sabemos que nas ciências sociais a estrutura das movimentações científicas não pode unicamente narrar sua história do mesmo modo que o olhar de Kuhn (1975) nos propõe. Primeiro, a) porque ali não há revoluções, pelo menos no sentido do autor, que coloca o termo revolução sob as condições da exclusão e substituição. Acreditamos ser oportuna a revisão, para o debate, das fronteiras do conceito de revolução, anteriormente já mencionado. Esse conceito pode adquirir significados divergentes - e talvez seja, dentre outras, uma das entidades que tornam conflituosa a importação e adoção do termo paradigma de Thomas Kuhn (1975) nas diferentes disciplinas além-ciências naturais. A revolução tanto pode ser prejudicial - causar insegurança, ainda que traga respostas - como ser satisfatória, ainda que falhe em suas promessas. $E$ há que se ver, do mesmo modo, as estratificações das manobras revolucionárias, ou seja, determinadas categorias são afetadas negativamente, outras positivamente. Essa descontinuidade não necessariamente se dá pela concordância - adoção - ou não de um paradigma. Po-

iniciais. demos, em uma análise, estudar a situação de um pesquisador que sempre militou marginalmente por um diferente curso de pensamento e, quando suas idéias passaram a ser sedimentadas como um novo paradigma, esse é simplesmente visto como pensador arcaico, e não necessariamente como pioneiro, uma vez que os "jovens" cientistas traduzem de modo mais claro as novas idéias para o jogo discursivo em questão - o que é natural, uma vez que são esses jovens, de certo modo, naquele contexto, já sob a sombra de uma outra gramática e um outro conjunto de significados para um vocabulário, que empreendem a sedimentação de uma outra esfera paradigmática, sem obrigatoriamente recorrer/citar um pensador marginal não contemporâneo. ${ }^{5}$

$5 \mathrm{Em}$ artigo recente, Cícero Araújo (2002), reflete sobre o termo revolução em Arendt, onde existe uma distinção normativa entre revoluções desejáveis, as revoluções dos conselhos, empreendidas por uma elite de autênticos cidadãos, e revoluções indesejáveis, fadadas à violência e ao terror, feitas pelas massas. Esta distinção teria inspirado Habermas, segundo o autor, a imaginar as manifestações espontâneas da sociedade como revoluções bem comportadas. Outros pensadores que se entretiveram com o conceito de revolução, como o citado Habermas e Ackerman, são revisados. Ackerman também realiza sua distinção entre revoluções desejáveis e indesejáveis - as primeiras, não visam uma revolução total nas relações econômico-sociais. Entre todos os pensadores, Cícero Araújo (2002) verifica o debate possível entre ambas as fundamentações do conceito de revolução. Isto significa estender nossa crítica ao conceito de "revolucionário" em Kuhn, caminhando por outra sensibilidade: há, em todo paradigma kuhniano, uma idéia de revolução desejável, uma vez que esse novo modelo responde pelas necessidades estruturais do contexto desafiado. No entanto, como na abordagem de Ackerman, são justamente as revoluções desejáveis - ou seja, sustentáveis, não 
Em segundo lugar, b) não há eliminação das teorias em sentido absoluto, pois dentro de uma comunidade científica sobrevivem idéias que continuam sendo manifestadas, ainda que inutilizadas por certos pares. Exemplo é a própria experiência da "revolução" terminológica ocorrida nas instituições de ensino e pesquisa em $\mathrm{Bi}$ blioteconomia, Bibliografia e Documentação, que tiveram seus nomes alterados para Ciência da Informação - essa, para muitos, um novo paradigma. Uma vez analisada em seus significados, a alteração não transformou, excluiu ou substituiu os conteúdos gerais dessa área de investigação, posicionando-se, em algumas vezes, como a reafirmação desses sob a imagem de outros termos; c) não há a constituição de paradigmas únicos e incomunicáveis de orientação por um determinado período; há, acreditamos, a coexistência e a retroalimentação de teorias - algumas claramente mais bem sucedidas em termos de aplicação do que outras -, diante da multiplicidade de interpretação do social que cada pesquisador propõe; d) as ciências

sumárias e desreguladas, ou etnocidas desdobramentos não absolutos, processos de transformação que não podem ser totalizados, pois nunca alteram de maneira radical as relações sociais em questão, deixando, em alguns casos, profundos traços retraduzidos para a nova gramática conjugada culturalmente. Em Thomas Kuhn (1975), a revolução diz respeito a substituição de um conjunto de suposições por outro. Essa substituição pode ser abrupta ou gradual, mas não deixa de definir, em um tempo, o desaparecimento completo daquele pensamento antigo que permitia determinados modelos de tomada de decisão, o que fica claro diante da idéia da sociais não sobrevivem necessariamente sob a promessa de uma teoria segura, mas, muitas vezes, caminham na instabilidade teórica reflexiva da sociedade que busca compreender - em outras palavras, essas ciências parecem estar permanentemente mais propensas ao imprevisto da diversidade de leituras sobre o mundo social, do que a regularidade de uma só macro-leitura ${ }^{6}$.

De um modo geral, pensar a ciência como Kuhn (1975) nas ciências sociais pressupõe, primeiro, discutir a proximidade e as distâncias entre essas e as ciências naturais, já que o autor parte basicamente da Física para fundamentar seu conceito de paradigma. Uma vez definida essa rela-

incomensurabilidade dos paradigmas.

6 Exemplo que acreditamos interessante para o tema "paradigmas nas ciências sociais" seria a relação histórica entre os trabalhos de Emile Durkheim e Gabriel Tarde, dois pioneiros da própria idéia de uma ciência social, o primeiro, amplamente discutido e revistado, o segundo, recuperado parcialmente e pouco investigado no âmbito das ciências sociais, em relação a Durkheim. No entanto, não é necessário caminhar muito. Uma história de duas definições do conceito Ciência da Informação poderia aprofundar essa discussão. Analisemos, por exemplo, os trabalhos de Borko e Jesse Shera entre os anos 1960/70. A definição de Borko (1968), ligada à Engenharia da Informação, se tornou clássica, mas não acreditamos que tenha se tornado um paradigma, ainda que, analisado os paradigmas em Kuhn (1975), ela tenha suas correspondências com o modelo do filósofo da ciência. A concepção de Borko (1968) repercute porque, dentre circunstâncias teóricas, legitima socialmente uma teoria prestigiada em seu tempo, a Teoria Matemática de Shannon e Weaver. No entanto, a formulação de Shera de uma $\mathrm{Cl}$ a partir da Epistemologia Social, ou seja, a partir de uma sociologia da ciência e uma sociologia para a informação, continuou ecoando nos estudos e nas práticas informacionais, uma vez que a Teoria Matemática não era capaz de abranger todos os problemas da informação, não poderia ser tomada 
ção e suas dicotomias, naturalmente a primeira opção que resta é afirmar: a maior parte das ciências sociais são préparadigmáticas, ou imaturas, como o próprio Kuhn (1975) teria demonstrado; a menor parte ainda nem atingiu esse estágio apenas existe como o rascunho de um projeto de institucionalização científica.

Assis (1993, p. 153) relaciona algumas razões que justificam porque as ciências sociais não podem ser posicionadas junto de uma ciência natural, como a Física, segundo o olhar de Kuhn.

Complexidade. Enquanto a física estuda eventos monótonos, a sociologia (ou a antropologia ou a política) estuda eventos em que intervêm fatores demais, o que torna qualquer situação difícil de controlar;

Autodecepção. Enquanto os objetos físicos não sabem o que se passa com eles, os objetos das ciências sociais o sabem. Assim, podem atuar contrariamente a suas intenções declaradas, frustrando qualquer possibilidade de pesquisa; Dificuldade em determinar o que seja um experimento. Enquanto em física é possível construir modelos que reproduzam características consideradas essenciais num sistema, para estudo controlado, o mesmo não pode ser feito com sujeitos humanos;

Repetibilidade. Um experimento em física pode ser repetido à vontade. Mas, numa sociedade humana, nada de análogo a um experimento pode ser feito. Não é possível repetir situações passadas. (grifo nosso)
Desta maneira, o futuro pode guardar um modelo unificado para as ciências sociais, um modelo satisfatório, cujas promessas atualizem permanentemente todas as angústias dos cientistas sociais. No entanto, esse modelo - inexistente até o princípio -, não seria tão rigoroso quanto a noção de paradigma de Kuhn. Soma-se ao discutido a questão da incomensurabilidade na ERC. Como afirma Parreiras (2006, p. 166-167), a idéia de incomensurabilidade no filósofo, mesmo retomado pelo autor em discussões posteriores de tentativa de clarificação do termo, é outra chave para a formulação do seu paradigma. Como o debatido, a revolução proporcionada pelo novo paradigma, na visão de Kuhn (1975), substitui o paradigma anterior, seja de maneira instantânea ou em etapas, mas caminha até apagar as visões de mundo anteriores.

Entre os paradigmas há lacunas históricas, "a ausência de comunicação e de relações entre tradições distintas" (FEITOSA; BARBOSA, 1997, p. 165). Não há continuidade, por isso não pode haver comensurabilidade. Há o que Feitosa e Barbosa (1997, p. 165) chamarão de "saltos". As teorias emergem como novas "especialidades" científicas. No entanto, "esta 'especiação' kuhniana diverge da de Darwin ${ }^{7}$, pois,

7 Pode-se encontrar correspondências primárias entre a teoria darwinista de evolução das espécies e a teoria kuhniana de progresso da ciência. Darwin viveu em um contexto em que agricultores e criadores se esforçavam para melhorar a qualidade

como uma teoria unificada. 
naquele caso, não há um processo de continuidade, mas, sim, de ruptura, de destruição de idéias anteriormente existentes" (PARREIRAS, 2006, p. 180). Essa associação, para Kuhn, como percebe Parreiras (2006), é totalmente desarmônica. Enfim, nas ciências exatas há, essencialmente, um objeto a ser descoberto, decifrado e controlado, ou uma descoberta ou um evento a ser explicado; nas ciências sociais e humanas há, estruturalmente, um objeto dinâmico, mutante e acelerado por se compreender - e essa compreensão só se dá na ampla comensurabilidade dos pontos de vista sobre a instabilidade do social.

O paradigma, diante da dinâmica do objeto das ciências sociais - o homem e suas relações - se apresenta como aquilo que Mills (1975) chamaria de um totalitarismo científico. Em outras palavras, o complexo que envolve a teoria e os teóri-

de seus animais e de suas plantas. O princípio era escolher as melhores espécies - aquelas que geravam bons resultados e cobriam as expectativas - e reproduzir sucessivamente estas categorias, segregando-as das demais. $\mathrm{O}$ projeto teórico darwinista se sustentaria nesta correlação. A construção do filtro biológico se daria por seleções sucessivas. Aqueles que melhor se adaptavam, sobreviviam. $E$ assim as espécies chegaram até ali: em contínuas interseções que foram produzindo categorias mais resistentes e condenando as demais ao desaparecimento (JAPIASSU, 1991). Em Kuhn, do mesmo modo, há um filtro no ciclo de expectativas das comunidades científicas que seleciona as melhores promessas e substitui essas, descartando as anteriores. No entanto, como verifica Parreiras (2006), na ERC há a extinção dos próprios traços de fundamentação do paradigma anterior, enquanto na Origem das Espécies não ocorre essa anulação sensível, uma vez que as novas espécies trazem, visivelmente, uma soma de características advindas dos cruzamentos históricos e contínuos, o que permite, por sua vez, a cos do novo paradigma se apresentaria como "o estadista da inteligência: pelo seu prestígio, parece prometer que a Teoria e a Pesquisa não só são compatíveis como também partes de um modelo de trabalho integrado na ciência social como um todo" (MILLS, 1975, p. 122). O paradigma, preocupado com a resolução de um problema, concentraria pesquisadores em um método específico e salvador, até que outro método aparecesse. Em um olhar mais crítico, o paradigma pode, em determinados casos, não se tornar um método eficiente, mas apenas uma promessa retoricamente bem formulada que perdura no discurso, mas não afeta a prática de pesquisa.

\subsection{Kuhn na Ciência da Informação: refletindo sobre as incongruências do uso}

Revisando alguns usos da visão paradigmática de Thomas Kuhn na $\mathrm{Cl}$, verificamos uma certa extensão dos pontos discutidos sobre a aplicação do trabalho de Assis (1993) dentro das ciências sociais. Naturalmente, a $\mathrm{Cl}$ tem suas peculiaridades teóricas e práticas e demanda a análise específica dentro de sua epistemologia. Mesmo quando reconhecemos seu território como localizado dentro das ciências sociais, é preciso visitar algumas condições para o uso/não-uso da abordagem de Kuhn (1975). Apresentamos, desta maneira, argumentos que indicam, em nosso olhar,

verificação da teoria darwinista. 
incongruências do uso das noções kuhnianas de atividade científica, como ciência pré-paradigmática, crise, ciência normal, revolução e paradigma na epistemologia informacional.

$O$ ponto mais sensivel que a adoção da filosofia de Kuhn atinge dentro da $\mathrm{Cl}$ é, em nossa leitura, a construção da historiografia da área, a qual se integra, naturalmente, a sedimentação de uma epistemologia específica para a informação. Sob a ótica paradigmática kuhniana, o desenvolvimento do pensamento historiográfico informacional assume uma linha forte de anulações de correntes teóricas e práticas, como se uma dada abordagem dentro da área fosse extinguindo outra. Sob essa ótica, parte considerável dos historiadores da área começam a enxergar uma "ciência para a informação" a partir da Segunda Guerra Mundial, quando uma engenharia computacional se desenvolve e permite um processamento de dados mais rápido e eficiente, em termos quantitativos. As novas tecnologias, que substituíam o catálogo de fichas e o microfilme, dentre outros instrumentos de meta-representação do conhecimento, anulavam métodos e teorias passadas, conduzindo a novos paradigmas. É através do mesmo modelo de pensamento científico kuhniano que esse grupo de historiadores e epistemólogos apontam as diferenças entre a Biblioteconomia e a Ciência da Informação - e, para alguns, a diferença entre Biblioteconomia, Documenta- ção e Ciência da Informação. Biblioteconomia e Ciência da Informação são áreas diferentes, ainda que complementares, dirão esses autores. E são diferentes, pois partem de paradigmas diferentes. A primeira, o paradigma da coleção; a segunda, o paradigma da informação ${ }^{8}$.

É fácil perceber que a história social e institucional da $\mathrm{Cl}$ não ocorreu dessa forma, como uma anulação, a partir de deslocamentos não-cumulativos, através dos saltos da ótica paradigmática kuhniana ${ }^{9}$. Não só a $\mathrm{Cl}$ tem sua raiz na Biblioteconomia clássica, como dirá Capurro (2003), como a caminhada da especialização dessa Biblioteconomia, passando pela Biblioteconomia especializada propriamente dita - industrial, empresarial e acadêmica -, pela Bibliografia - estatística e textual -, pela Documentação, até chegar a $\mathrm{Cl}$, é um deslocamento cuja movimentação circular e dialógica é culturalmente identificável. Desta maneira, não nascerão, na maior parte dos episódios, edifícios isolados - institutos, centros de pesquisa e faculdades trazendo o nome de uma nova ciência. Serão os edifícios de Biblioteconomia, Documentação e Bibliografia que terão seus nomes transformados ao longo dos últimos 40 anos.

8 Coelho (1996), Bulik (1996), e Oliveira (1996) estão entre as vozes que problematizarão esta condição paradigmática.

9 Um esclarecimento desse ponto de vista pode ser percebido no trabalho de Mostafa (1996), principalmente na visão da pesquisadora acerca da dialética entre documento e informação. 
Do mesmo modo, a divisão paradigmática em momento algum pode ser tida como clara, pois o chamado paradigma da informação sempre foi exercido, principalmente na Biblioteconomia clássica, erudita, quando o conhecer era mais relevante que o classificar - e mesmo a Biblioteconomia especializada, essa que possuía, como seu leit motiv, o processo de referência, fundamentalmente voltado para a informação, e não para a coleção. É exatamente a especialização da Biblioteconomia clássica que dará origem a $\mathrm{Cl}$, que, em verdade, a princípio, não comungava teoricamente nem de um paradigma da informação nem da coleção, mas, diríamos, se usássemos a lógica de Kuhn (1975), um paradigma da transmissão de sinais $^{10}$. Posteriormente, como as próprias cartas de justificação para alteração de nomes de escolas e institutos de pesquisa em organização do conhecimento refletiam, como em Barbosa et al. (2000), o paradigma da informação já era adotado, inclusive, nos currículos das escolas de Biblioteconomia e Documentação, comunicando-se paralelamente com o paradigma da coleção, esse que continua e

10 Nunes (1996) reflete sobre esta situação paradoxal dentro da epistemologia da $\mathrm{Cl}$. Como afirma o autor, é "impróprio falar em novo paradigma quando não se tem um paradigma estabelecido, daí a impropriedade de falar-se em crise, que justifique a anunciação da boa nova" (NUNES, 1996, p. 86). Em outras palavras, sob a ótica paradigmática, como visto, a $\mathrm{Cl}$ estaria em vias de existir, e se escorava oportunamente em conceitos e teorias contemporâneas, como pós-modernidade, interdisciplinaridade e mudança de paradigma para se fazer científica. continuará vigente, pois ambos são indissociáveis.

Nota-se, ainda, que a transformação dos nomes responde também por uma questão mencionada na crítica de Assis (1993): a busca da respeitabilidade e da visibilidade científicas das ciências não exatas, imagem essa que as nomenclaturas anteriores pareciam, no olhar dos pesquisadores que propunham a alteração, não permitir, mesmo os currículos já tendo sido alterados em grande parte das escolas, pelos mesmos pesquisadores. Diversos cientistas em $\mathrm{Cl}$, como Capurro ${ }^{11}$ nos contarão uma história da área a partir da institucionalização terminológica da expressão "ciência da informação" no mundo ocidental,

11 O próprio Capurro (2003) chama atenção para o fato dessa periodização representar um problema, pois antes de 1945 já havia o que ele classifica como paradigma social, manifestação identificada pelo autor como demarcada pelos anos 1980/1990. Aqui, percebemos: o autor, ao demonstrar que em sua origem a área, mesmo vivenciando um paradigma físico, comportava outro, social, já contradiz o uso do termo. Lembremos, na mesma linha de argumentação, que, em pleno ano de 1996, Ingwersen está falando de abordagem cognitiva quando, na periodização de Capurro (2003), já estamos sob a muralha do paradigma social. A corrente cognitiva não é uma anomalia em $\mathrm{Cl}$. No entanto, aparece em uma década em que a área estaria consideravelmente mais voltada para um enfoque social. Estas ocorrências paralelas apenas voltam a demonstrar que as tradições sempre conviveram - e se comunicaram - amplamente dentro da $\mathrm{Cl}$, evidência que será melhor compreendida na análise final da viagem à tradição pragmática, onde podemos perceber como o diálogo com os enfoques pragmáticos redirecionam e aprofundam os demais enfoques na área, como da abordagem cognitiva e da abordagem matemática ou física. Ou seja, compreendemos, nessa verificação capurriana, a existência de uma comensurabilidade entre escolas da informação aparentemente excludentes, mas não paradigmáticas. 
como se esse fosse um novo paradigma, independente do que outrora fora construído ${ }^{12}$.

Para além da questão historiográfica, outros elementos são igualmente importantes na revisão da adoção da ERC dentro dos estudos informacionais. Apresentamos, a seguir, a síntese crítica de algumas sensibilidades para a reflexão crítica da adoção de Kuhn na epistemologia da $\mathrm{Cl}$.

a) a existência de três paradigmas na $\mathrm{Cl}$, como pressupõe Capurro (2003), precisa ser reavaliada. Prescrever o desenvolvimento da área a partir de uma seqüência paradigmática físico, cognitivo e social, seria afirmar, inicialmente, segundo a ótica de Kuhn (1975), que um paradigma foi anulando outro em períodos não-cumulativos, o que não ocorreu; em segundo lugar, que houve um consenso geral em torno de cada teoria, o que também não existiu e não existe, dada a profusão de trabalhos de revisão e crítica; que se verificou uma revolução científica na passagem desses paradigmas, o que não pode ser dito - ainda há muito que se explorar sobre as pesquisas matemáticas e cognitivas da informação; e, finalmente, que a $\mathrm{Cl}$ passou por três períodos estáveis de ciência normal, o que parece também não ter ocorrido, uma vez que a própria defini-

12 São exemplos desta linha historiográfica, além do já mencionado Capurro (2003), Rendón Rojas (1996) e Zunde e Gehl (1972). ção de uma Ciência da Informação permanece como tema de debates ${ }^{13}$. Acreditamos que, se se quer falar de grandes teorias no desenvolvimento da área pensamos que, em parte, um dos principais intuitos no trabalho de Capurro (2003), essencialmente preocupado com o que foi e o que é a epistemologia da $\mathrm{Cl}$, e com uma historiografia perdida da área -, mais adequada, para o caso específico, seria a divisão realizada por

13 É verdade que o próprio Capurro (2003), na abertura de seu artigo Epistemologia e Ciência da Informação, levanta a crítica realizada por Margaret Masterman e David Ellis, e observa que sua utilização do termo "paradigma" é esquemática como lembrado por Matheus (2005). No entanto, Capurro (2003), como já citado, não aprofunda a discussão compreensiva sobre o que pressupõe a importação do termo para a $\mathrm{Cl}$, apreendendo, de forma explícita, o desenvolvimento desta disciplina como um desdobramento de três períodos paradigmáticos. Além disso, o autor usa o termo também, de forma esquemática, no trabalho What is Information Science for? a philosophical reflection, de 1991, trabalho revisado e reeditado sob o nome de Foundations of information science: review and perspectives (2007). A própria citação do trabalho de Hjorland e Albrechtsen (1995) acerca da análise do domínio verifica o uso generalizado realizado por Capurro (2003). O autor identifica a proposta de Hjorland e Albrechtsen (1995) de um paradigma para a $\mathrm{Cl}$. Uma leitura crítica da ERC pode sustentar que a idéia de propor um paradigma tende a parecer paradoxal, uma vez que paradigmas são, antes de tudo, crenças e valores compartilhados, e posteriormente impostos sobre outros discursos discordantes - assim sendo, poderíamos falar na proposta de uma nova teoria no vocabulário kuhniano, e não na sugestão de um paradigma. O paradigma, enquanto processo cultural, não existe a priori, mas é uma construção conjunta e dinâmica. Nossa leitura crítica aqui parte da seguinte argumentação: é possível propor um paradigma segundo a ótica de Thomas Kuhn? Nossa resposta, para tal, é não. É possível propor, na ERC, a identificação e a revisão de anomalias, não paradigmas. Os paradigmas não são produto de descobertas, mas de consenso. Só acontecem após um certo pleito, com campanhas, debates, publicidade, críticas e, principalmente, promessas retoricamente bem elaboradas e aplicação 
Rendón Rojas (1996), isto é, na existência de grandes teorias dentro da epistemologia dos estudos informacionais, uma teoria inicial chamada sintática, uma posterior chamada semântica, e, por fim, um flexível enfoque pragmático;

b) a $\mathrm{Cl}$, vista como uma ampla rede social de comunidades de pesquisadores, poderia verdadeiramente estar atrás de um paradigma, do qual dependeria para sobreviver na ecologia científica? Diferente daquilo que, de um modo geral, poderia angustiar Lenzi e Brambila (2006), França e Perez (1996) e Nehmy et al. (1996), $a$ área de estudos informacionais, como as demais ciências sociais, não comporta um consenso geral - não pode e nem deve sustentar-se a partir de um macroconsenso, a macro-teoria da informação - e a dispersão das correntes informacionais demonstra o distanciamento desse ecumenismo. Wersig (1993) e Silva (1999) lembram/diagnosticam que a $\mathrm{Cl}$ dificilmente abrigaria essa macro-teoria. A profusão de propostas teóricas e metodológicas na área já corrobora essa evidência. Enquanto ciência que faz, dentre outras múltiplas atividades, uma leitura das disciplinas do conhecimento - recolhe, reconhece, classifica, organiza e preserva os documentos produzidos pela ciência - a epistemologia informacional se movimenta sob um golfo

dogmática de suas regras. cercado por inumeráveis faróis. Isto não significa dizer que os determinados autores, em diferentes momentos, acreditem ter identificado uma teoria ecumênica na área, mas isto pode ser caracterizado, diante dos múltiplos de olhares que a solidariedade teórica da $\mathrm{Cl}$ agrega, como um ponto de vista original dentre outros ${ }^{14}$. Como afirma Mills (1975, p. 56), na análise das macro-teorias dentro das ciências sociais, as teorias unificadoras parecem "embebedar-se de sintaxe", e "perder a audição para a semântica", ou seja, "não há uma grande teoria, nenhum esquema universal em termos do qual possamos compreender a unidade da estrutura social, nenhuma resposta ao velho e cansado problema da ordem social".

c) a $\mathrm{Cl}$ deve ser considerada subdesenvolvida ou imatura por não ser paradigmática? Ao contrário, podemos, através de dois ângulos, problematizar essa hipótese pela relação contrária. Partindo de considerável parte da historiografia da $\mathrm{Cl}$, como aquela apresentada por Pinheiro (1997), Robredo (2003) e Wersig (1993), entendendo a área como uma ciência construída nos eventos que cir-

14 A revisão de uma proposta de macro-teoria dentro da $\mathrm{Cl}$ sempre termina por revelar que esta, na verdade, se adequa mais a um campo fronteiriço da área, específico, e não a todas as suas práticas, como foi o exemplo da revisão da Teoria Matemática de Shannon \& Weaver, que se viu mais próxima de uma Engenharia da Informação, não de uma $\mathrm{Cl}$ como um todo. 
culam a Segunda Guerra Mundial, tendo o conceito de pós-modernidade como um de seus pilares junto dos pressupostos de uma epistemologia da complexidade, poderíamos dizer, como o faz o próprio Wersig (1993), que a Cl é das poucas ciências da contemporaneidade, das poucas ciências que hoje respondem pelo que se pode chamar de científico, pois se apresentaria, como no olhar dos autores citados e de muitos outros, como ciência interdisciplinar; se partirmos de uma historiografia que recupera a $\mathrm{Cl}$ como o deslocamento institucional e terminológico dos estudos de organização do conhecimento - voltados para a meta-representação e transmissão de conteúdos e a preservação de formas -, tendo suas bases práticas e teóricas na Biblioteconomia clássica, percebemos que a $\mathrm{Cl}$ nasce no âmbito das ciências sociais, apresentando já uma idade considerável, apenas devedora das mais antigas ciências formalizadas, como a Física. Lembremos, o conceito de ciência não é um paradigma kuhniano em nenhuma comunidade científica - estamos deliberadamente seguros quanto a uma noção geral do que é ciência? Sem dúvida essa idéia é uma falsa salvaguarda - e os estudiosos da filosofia contemporânea da ciência, como Bourdieu, Latour, Bachelard, Boaventura Santos, e o próprio Kuhn (1975), chamaram atenção para isto. O paradigma "ci- ência" nos fez acreditar - e nos provou na maioria das vezes ser uma promessa passível de desdobramentos eficazes que tudo o que é científico é bom e/ou útil para nosso progresso, pois é fruto da racionalidade. Como afirmou Moles (1995, p. 64) "é útil examinar as limitações de fato do poder do científico e reconhecer a impossibilidade de atingir certas verdades que parecem perfeitamente 'científicas' do ponto de vista do pensamento racional". O paradigma "ciência" o que fez, em muitos casos, ao invés de desvelar razões práticas, foi encobrir e/ou apoiar e sustentar grandes erros de interpretação da realidade e da humanidade. Não há um consenso definitivo-local sobre o que é ciência - como afirma Mills (1975, p. 23), em sua Imaginação Sociológica, "muito do que se considerava como 'ciência' passou a ser visto hoje como uma filosofia dúbia"; ou, "a palavra 'ciência' adquiriu grande prestígio e um sentido bastante impreciso". Há, na verdade, revisões históricas que nos demonstram as diferenças entre ciência, teologia e filosofia; há delineamentos discursivos que contribuem para nossa referência acerca do que é acientífico; há instituições legitimadas que demonstram onde a ciência procura se definir; mas dizer "ciência é isso - e apenas isso -" não é cabível, mesmo em uma comunidade específica. Como sabemos, a imposição de certos paradig- 
mas sobre o conceito de ciência conduziu a barbárie, e não ao progresso. ${ }^{15} \mathrm{Se}$ determinados critérios demarcatórios, teorias e métodos de outras áreas não se aplicam às ciências sociais e humanas, como lembrado por Ribeiro (2003), isso não quer dizer, necessariamente, que essas últimas estejam em uma infância lenta e atávica, mas simplesmente por possuírem em sua produção diferenças elementares com as demais ciências. As semelhanças - suas compatibilidades verificáveis - existem, mas não podem encobrir e negligenciar as dicotomias mútuas, as especificidades de cada saber.

d) se a emergência de novas teorias é precedida por um momento de insegurança

15 Japiassu (1991) demonstra o desenvolvimento da teoria eugenista, de Francis Galton (1822-1911), e de outros desdobramentos do paralelismo entre os trabalhos de Charles Darwin e a evolução humana. O eugenismo de Galton visava a preservação das raças consideradas geneticamente mais elevadas, e pregava a omissão àquelas consideradas desprivilegiadas intelectualmente. Desta forma, sustentada cientificamente, a proposta atingirá o imaginário social a partir da imposição de uma corroboração paradigmática de que alguns homens são melhores que outros, por isso sobreviverão, por isso ocupam os melhores cargos e níveis sociais, por isso não devem ser cruzados com as raças inferiores, pois essa condição diminuiria as possibilidades de evolução e sobrevivência do gênero humano. Como lembra Japiassu (1991), em suas metodologias, a ciência, por vezes, se recusa a traçar juízos de valor, quando, na verdade, é cada vez mais dominada por forças políticas, dinamizando a tecnologia que, por sua vez, permite a dinâmica da indústria da paz e da guerra. Em outras palavras, acreditar em um paradigma pelo fato científico de que esse atende às nossas expectativas - nos satisfaz - é assumir a crítica molesiana da ditadura metodológica, a própria capitulação paradigmática, a formulação de que da medida tomada como método chega- profissional, com a destruição de paradigmas anteriores, a $\mathrm{Cl}$ não apresentaria, em suas próprias tendências culturais, a identidade de uma disciplina paradigmática, pois essa "insegurança" de que nos fala Kuhn (1975) é uma das características fundamentais da área. Se nos baseássemos nesse pressuposto - que cada crise abre caminho para um novo paradigma - diríamos que a $\mathrm{Cl}$ é uma usina de paradigmas, constatada a dimensão múltipla de seus projetos de pesquisa e heterogeneidade de suas teorias. $\mathrm{A} \mathrm{Cl}$ é fruto da crise, pois sobrevive no complexo estudo de compreensão das linguagens que constroem o conhecimento e permitem seu uso - e sua sobrevivência, acreditamos, até certo ponto, só existe na crise - ou na possibilidade de identificação de crises - a "crise" do nascimento da escrita e da filosofia política na Antiguidade, levando a constituição de bibliotecas, como a de Alexandria, para guardar o conhecimento; a "crise" do século XIX, com o nascimento de novas instituições, exigindo das bibliotecas serviços especializados, o que imprimiu grande expressão à disciplina Bibliografia, semente da Documentação; a "crise" da superprodução de documentos verificada no início do século $X X$, que leva até a condução de novas formas de armazenamento do cose até a medida como frenesi, e o frenesi do racio- 
nhecimento, como a exploração da micro-fotografia.

e) ainda dentro do raciocínio anterior, parece não existir uma incomunicabilidade permanente entre as principais teorias dentro da $\mathrm{Cl}$. Ao contrário, há um permanente intercâmbio de habilidades e conhecimentos. O vocabulário de Shera (1973) demonstra como sua Epistemologia Social tem forte influência cognitiva, marcada na fronteira do período que poderíamos chamar da virada cognitiva. Há vários outros autores e trabalhos marginais, junto de Shera, como Belkin, Brookes, Merta, Mikhailov, Roberts, Wersig, todos tratando, de certa forma, de um fundamento mais "social", e menos "físico", para a área, porém dialogando com ambas as tradições que ali se sedimentavam. Esses investigadores contribuíram para o desenvolvimento do fisicalismo e do cognitivismo em $\mathrm{Cl}$ como contribuem para a compreensão do pragmatismo informacional -, sem serem adeptos e, simultaneamente, sem serem anulados.

f) por fim, a $\mathrm{Cl}$, podemos argumentar em uma outra figura de linguagem, não teria momentos de paz epistemológica, o armistício hermenêutico da ciência normal de Kuhn ${ }^{16}$ - mas sempre se encontra na

nal não é em si uma racionalidade. (MOLES, 1995) 16 Kuhn (1993) argumenta que, durante o período de ciência normal, quando o paradigma é sedimentado e orienta os pesquisadores da área, há um período de apaziguamento, um cessar fogo nas revisão permanente da interpretação dos discursos, buscando as possibilidades de meta-representá-los e transmitilos. Seria necessária - e realmente possível - a condição de uma suspensão momentânea da discussão sobre os fundamentos da ciência e da teoria conjugada, como argumenta Kuhn (1975)? Por que a $\mathrm{Cl}$ deve parar de se perguntar o que é e o que não é uma Ciência da Informação? Racionalmente, não encontramos motivo. Epistemologicamente, muitos menos.

\section{CONSIDERAÇÕES FINAIS}

A questão de ser ou não ser ciência é tema corrente dentro da epistemologia geral, e aparece como o sintoma de uma patologia. A $\mathrm{Cl}$ talvez traga em seu corpo de fundamentação e justificação social o vírus dessa doença - e esse ataca de tempos em tempos. As próprias justificações a) de alteração do seu nome de suas instituições de pesquisa e b) de existência a partir da interdisciplinaridade, e não de sua especificidade, são evidências dessa angústia inaugural.

Como afirma Assis (1993, p. 160),

[...] o cientista social, seja antropólogo, cientista político,

argumentações. As discussões praticamente desaparecem. Seria uma espécie de ciência fria, momento em que os pesquisadores estão mergulhados nas trilhas oferecidas pelo paradigma e preparam, de certa forma, as novas descobertas que podem tornar-se paradigmas futuros e identificam e separam as anomalias. 
historiador, etnógrafo, lingüista, continua a fazer suas pesquisas como sempre fez, baseado em seus próprios métodos. Pouco importa se existe constante debate acerca de fundamentos, pouco importa se deve ou não chamar a sociologia de ciência (ou questões parecidas: é a história objetiva?, tem a sociologia um paradigma? etc.), o que importa é que essas disciplinas contribuam para a criação de um objeto de comparação que elucide o que é a racionalidade ou, melhor, como é ela numa dada época.

A crítica às ciências do homem resta mais sobre a questão da linguagem nãomatematizada. Recai ainda sobre a questão de que, uma vez não fundamentada pelas leis matemáticas, esse saber é apenas uma troca de opiniões, ou seja, as ciências sociais e humanas se resumem à doxa, a opinião. No entanto, se

[...] nossa linguagem é tão próxima da natural (...), é porque está na essência mesma das ciências do homem a passagem do discursosobre ao discurso-com e por vezes ao discurso-de. Em outras palavras, o sentido essencial de nossas ciências é o de efetuar a translação da terceira pessoa do discurso, no qual ela opera inicialmente (falando dos homens com "eles"), para uma linguagem dialogada e, finalmente, para uma primeira pessoa. Por isso é que o empreendimento das Humanas (ou, vale retomar, das Humanidades) se mostra emancipador. (RIBEIRO, 2003, p. 98-99).

Thomas Kuhn abre, com sua ERC, o espaço para a entrada e a identificação da doxa na compreensão do desenvolvimento da ciência. Além disso, apresenta um profundo e original trabalho para analisar o desenvolvimento de determinados grupos de pesquisa. No entanto, conduz-nos a percepção de apenas um ângulo de compreensão da atuação desse conjunto de crenças compartilhadas, o ângulo da imposição paradigmática e da anulação de vozes marginais no discurso científico. Cabe-nos pensar não apenas na concorrência científica, mas também na solidariedade teórica.

Essa solidariedade, muito explorada por Rorty (1997) é uma identidade da Cl como lembra González de Gómez (2001, p. 14), uma "guardiã da comensurabilidade dos discursos científicos" -, como da Documentação, da Bibliografia, da Biblioteconomia. Adotar o modelo de pensamento sobre a atividade científica de Kuhn implica em uma desconstrução dessa identidade, bem como esvazia uma historicidade cumulativa que nos permite compreender e evitar, dentre outras situações, as repetições de erros clássicos na história dos estudos de organização do conhecimento, como aquele que acreditava que a Engenharia da Informação poderia substituir o homem no trato da metarepresentação e, principalmente, da transmissão do conhecimento.

\section{REFERÊNCIAS}

ARAÚJO, C. Entre o Estado e a Revolução. Rev. Bras. Ci. Soc., São Paulo, v. 17, n. 49, p. 39-54, jun. 2002. 
ASSIS, J. P. Kuhn e as ciências sociais. Estud. Av., São Paulo, v. 7, n. 19, p. 133164, dez. 1993.

BARBOSA, R. R. et al. Novo nome e novo paradigma: da biblioteconomia à ciência da informação. Perspect. Cienc. Inf., Belo Horizonte, v. 5, n. Especial, p. 81-91, jan./jun. 2000.

BORKO, H. Information science: What is it? American Documentation, Washington, $\mathrm{v}$. 19, n. 1, p.3-5, Jan. 1968.

BULIK, L. Globalização da informação: imperialismo ou parceria: o paradigma da informação na era da globalização. In: SIMPÓSIO BRASIL-SUL DE INFORMAÇÃO, 1., 1996, Londrina. Anais... Londrina: UEL/Departamento de Biblioteconomia, 1996. p. 46-63.

CAPURRO, R. Epistemologia y ciencia de la información. In: ENCONTRO NACIONAL DE PESQUISA EM CIÊNCIA DA INFORMAÇÃO, 5., 2003, Belo Horizonte. Anais... Belo Horizonte: Escola de Ciência da Informação da UFMG, 2003.

COELHO, T. Do paradigma do acervo para o paradigma da informação. In: SIMPÓSIO BRASIL-SUL DE INFORMAÇÃO, 1., 1996, Londrina. Anais... Londrina: UEL/Departamento de Biblioteconomia, 1996. p. $15-30$.

EUGÊNIO, M.; FRANÇA, R. O.; PEREZ, R. C. A Ciência da Informação sob a ótica paradigmática de Thomas Kuhn: elementos de reflexão. Perspect. Ci. Inf., Belo Horizonte, v. 1, n. 1, p. 27-39, jan./jun. 1996.

FEITOSA, M. C. A.; BARBOSA, M. J. Verdade e multiplicidade de métodos em Bachelard. In: BARRETO, J. A. E.; MOREIRA, R. V. O. (Org.). Imaginando erros: escritos de filosofia da ciência. Fortaleza: Casa de José de Alencar, 1997. p. 147-166. (Coleção Alagadiço Novo)

FOSKETT, D. J. Informática. In: GOMES, H. E. (Org.). Ciência da Informação ou in- formática? Rio de Janeiro: Calunga, 1980. (Série Ciência da Informação)

GONZÁLEZ DE GÓMEZ, N. M. Para uma reflexão epistemológica acerca da Ciência da Informação. Perspect. Ci. Inf., Belo Horizonte, v. 6, n. 1, p. 5-18, jan./jun. 2001.

HJORLAND, B.; ALBRECHTSEN, H. Toward a new horizon in information science: domain-analysis. Journal of the American Society for Information Science and Technology, New York, v. 46, n. 6, p. 400-425, 1995.

INGWERSEN, P. Cognitive perspectives of information retrieval inferaction: elements of a cognitive IR theory. J. Doc., London, v. 52, n. 1, p. 3-50, Mar. 1996.

JAPIASSU, H. A origem pseudo-cientifica do racismo. In: As paixões da ciência. São Paulo: Letras e Letras, 1991. p. 243-273.

KUHN, T. S. A estrutura das revoluções científicas. São Paulo: Perspectiva, 1975.

LAUDAN, L. et. al. Mudança científica: modelos filosóficos e pesquisa histórica. Estudos Avançados, v. 7, n. 19, p. 6-89, 1993.

LENZI, L. A. F.; BRAMBILA, E. Z. Ciência da Informação, ciência e revolução científica: breve histórico e reflexões. Inf. Inf., Londrina, v. 11, n. 1, jan./jun. 2006.

MATHEUS, R. F. Rafael Capurro e a filosofia da informação: abordagens, conceitos e metodologias de pesquisa para a Ciência da Informação. Perspect. Cienc. Inf., Belo Horizonte, v. 10, n. 2, p. 140-165, jul./dez. 2005.

MILLS, C. W. A imaginação sociológica. 4. ed. Rio de Janeiro: Zahar, 1975.

MOLES, A. A. As ciências do impreciso. Rio de Janeiro: Civilização Brasileira, 1995.

MOSTAFA, S. P. Filosofando sobre a área de informação. In: SIMPÓSIO BRASIL-SUL DE INFORMAÇÃO, 1., 1996, Londrina. 
Anais... Londrina: UEL/Departamento de Biblioteconomia, 1996. p. 31-45.

NEHMY, R. M. Q. et. al. A Ciência da Informação como disciplina científica. Perspect. Ci. Inf., Belo Horizonte, v. 1, n. 1, p. 9-25, jan./jun. 1996.

NUNES, C. O. I. Algumas considerações acerca da discussão da mudança de paradigma na ciência contemporânea e suas implicações para biblioteconomia/ciência da informação. In: SIMPÓSIO BRASIL-SUL DE INFORMAÇÃO, 1., 1996, Londrina. Anais... Londrina: UEL; Departamento de Biblioteconomia, 1996. p. 69-91.

OLIVEIRA, M. Os paradigmas da Ciência da Informação. In: SIMPÓSIO BRASILSUL DE INFORMAÇÃO, 1., 1996, Londrina. Anais... Londrina: UEL/Departamento de Biblioteconomia, 1996. p. 143-150.

PARREIRAS, M. M. M. Ludwik Fleck e a historiografia da ciência: diagnóstico de um estilo de pensamento segundo as Ciências da Vida. 2006. Dissertação. (Mestrado em História) - Faculdade de Filosofia e Ciências Humanas da Universidade Federal de Minas Gerais, Belo Horizonte.

PINHEIRO, L. V. R. A Ciência da informação entre sombra e luz: domínio epistemológico e campo interdisciplinar. 1997. Tese. (Doutorado em Comunicação e Cultura) Universidade Federal do Rio de Janeiro, Rio de Janeiro.

POPPER, K. R. A lógica da investigação científica. São Paulo: Abril, 1975. (Os Pensadores, 44

RENDÓN ROJAS, M. A. R. Hacia um nuevo paradigma em bibliotecologia. Transinformação, Campinas, v. 8, n. 3, p. 17-31, set./dez. 1996.

RIBEIRO, R. J. A universidade e a vida atual: Fellini não via filmes. 2. ed. Rio de Janeiro: Campus, 2003.
ROBREDO, J. Da ciência da informação revisitada aos sistemas humanos de informação. Brasília: Thesaurus, 2003.

RORTY, R. Objetivismo, relativismo e verdade. Rio de Janeiro: Relume-Dumará, 1997. (Escritos Filosóficos, 1).

SANTOS, B. S. Um discurso sobre as ciências. Porto: Afrontamento, 1993.

SHERA, J. H. Toward a theory of librarianship and information science. Ci. Inf., Brasília, v. 2, n. 2, p. 87-97, 1973.

SILVA, R. R. G. Ciência da Informação: perspectivas e indicativos para a ação. In: PINHEIRO, L. V. R. (Org.). Ciência da Informação, Ciências Sociais e Interdisciplinaridade. Brasília: IBICT, 1999. p. 119-129.

TOURAINE, A. Um novo paradigma: para compreender o mundo de hoje. Petrópolis: Vozes, 2006.

WERSIG, G. Information science: the study of postmodern knowledge usage. Inf. Process. Manag., Elmsford, v. 29, n. 2, p. 229239, 1993.

ZUNDE, P.; GEHL, J. Empirical foundations of Information Science. ARIST, White Plains, v. 14, p. 67-92, 1972.

\section{Title}

Thomas Kuhn in Information Science's epistemology: a critical approach.

\begin{abstract}
This paper discusses the presence of Thomas Kuhn in Social Sciences and Information Science. It presents some different statements concerning the use of the theories of the science's philosophy based on his book "The Structure of the Scientific Revolutions" which are applied in informational epistemology studies. It develops a critical reasoning about
\end{abstract}


the epistemology and the Information Science's historiography.

\section{Keywords}

Epistemology. Information Science. Paradigm. Thomas Kuhn.

\section{Título}

Thomas Kuhn en la epistemología de la Ciencia de la Información: una reflexión crítica.

\section{Resumen}

El artículo explora la presencia de Thomas Kuhn en las ciencias sociales y en la ciencia de la información. Identifica posibles incorrcciones en el uso de la filosofía de la ciencia sobre la Estrutura das Revoluções Científicas en la lectura de la epistemología de los estudios de la información. Se desarrolla una reflexión crítica sobre la epistemología y la historiografía de la Ciencia de la Información.

\section{Palabras Clave}

Epistemología. Ciencia de la Información. Paradigma.Thomas Kuhn.

Recebido em: 04.05.2008

Aceito em: 05.02.2009 